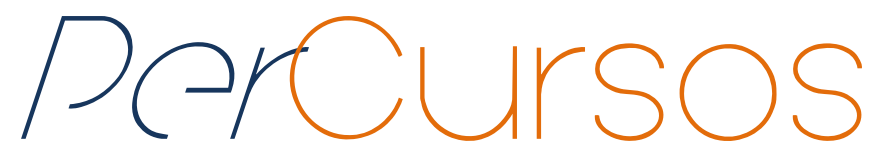

\title{
Mulheres e ação política: lutas feministas pelo direito à cidade
}

\begin{abstract}
Resumo
Entender a luta pelo direito à cidade a partir de uma perspectiva feminista pressupõe problematizar os paradigmas que sustentam o pensamento acadêmico. Esses fundamentos e as próprias políticas urbanas são muitas vezes o resultado das ações de homens que não reconhecem as demandas das mulheres em suas lutas diárias na cidade. O objetivo aqui é demonstrar o embate ideológico e político - do pensamento à ação - que se revela no fato de que a ciência historicamente negligenciou as mulheres que subvertem a ordem estabelecida. Questionar suposições epistemológicas da perspectiva científica predominante (masculina, branca, ocidental) é uma maneira de permitir que outros sujeitos e lugares de enunciação possam emergir. $O$ artigo direciona o olhar para as lutas feministas pelo direito à cidade, entendendo isso como o direito a uma vida urbana renovada e transformada. O movimento feminista, em sua pluralidade e diversidade como multiplicidade de movimentos de mulheres reivindicando seus direitos, revela-se em sua complexidade e as epistemologias feministas orientam as reflexões por meio das diversas abordagens possíveis. $O$ feminismo negro, o feminismo indígena e o transfeminismo indicam a necessidade de abordagens interseccionais para compreender as ações das mulheres na luta pelo direito à cidade e, mais amplamente, pelo direito ao próprio corpo e à própria vida. Essa luta se manifesta em protestos e ações políticas, mas também nas ações cotidianas de mulheres que se recusam a conformar-se aos limites e interdições que lhes são impostos, procurando elaborar políticas urbanas mais amplas e corporificadas.
\end{abstract}

Palavras-chave: Mulheres. Direito à cidade. Epistemologias Feministas.
Anita Loureiro de Oliveira

Geógrafa e Mestra em Geografia pela Universidade Federal

Fluminense (UFF).

Doutora em Planejamento

Urbano e Regional pela

Universidade Federal do Rio de Janeiro (UFRJ). Docente do Programa de Pós-graduação em Geografia e do Departamento de

Geografia do Instituto

Multidisciplinar da Universidade Federal Rural do Rio de Janeiro (UFRRJ).

Tutora do Grupo PET-

Geografia/IM - Bolsista PET-MEC. anitaloureiro@yahoo.com.br

\footnotetext{
Para citar este artigo:

OLIVEIRA, Anita Loureiro de. Mulheres e ação política: lutas feministas pelo direito à cidade. Revista PerCursos, Florianópolis, v. 19, n.40, p. 111 -140, maio/ago. 2018.
}

DOI: 10.5965/1984724619402018111

http://dx.doi.org/10.5965/1984724619402018111 


\title{
Women and Political Action: feminist struggles for the right to the city
}

\begin{abstract}
Understanding the struggle for the right to the city from a feminist perspective presupposes problematizing the paradigms that underpin the academic thinking. These underpinnings, and urban policies themselves, are often the outcome of the actions of men who do not recognize the demands of women in their daily struggles in the city. The aim here is to demonstrate the ideological and political clash from thought to action - that is revealed in the fact that science has historically neglected the women who subvert the established order. Questioning epistemological assumptions in the prevailing (male, white, western) scientific perspective is one way to allow other subjects and places of enunciation can emerge. The paper directs the gaze towards feminist struggles for the right to the city, understanding this as the right to a renewed, transformed urban life. The feminist movement, in its plurality and diversity as a multiplicity of movements of women calling for their rights, is revealed in its full complexity and feminist epistemologies guide the reflections through the many possible approaches. Black feminism, indigenous feminism, and transfeminism all indicate the need for intersectional approaches to comprehend women's actions in the struggle for the right to the city and, more broadly, the right to their own body and own life. This struggle is manifested in protests and political actions, but also in the daily actions of women who refuse to conform to the limits and interdictions imposed on them, striving to devise broader and embodied urban policies.
\end{abstract}

Keywords: Women; Right to the City; Feminist Epistemologies. 
"Vocês querem nos matar, nos controlar. Vocês não vão nos calar.

Mesmo sangrando a gente vai tá lá, pra marchar e gritar.

Eu sou Marielle, Cláudia, eu sou Marisa.

Eu sou a preta que podia ser sua filha." (MC Carol) ${ }^{1}$

A compreensão da luta pelo direito à cidade numa perspectiva feminista supõe uma problematização dos principais paradigmas que fundamentam a produção acadêmica e as políticas urbanas. Isso porque, tanto a produção acadêmica como as políticas urbanas, em grande parte, resultam da ação de homens que não reconhecem demandas apontadas por mulheres em suas lutas cotidianas, dentre as quais aquelas relacionadas à vida das mulheres nas cidades.

Para Lefebvre (2001, p.20), “a vida urbana pressupõe encontros, confrontos das diferenças, conhecimentos e reconhecimentos recíprocos (inclusive no confronto ideológico e político) dos modos de viver, dos 'padrões' que coexistem na Cidade”. Para o autor, o direito à cidade se manifesta como forma superior de outros direitos: direito à apropriação (diferente do direito à propriedade), direito à liberdade, à individuação na socialização e o direito à obra (à atividade participante).

A proposta deste texto é reunir ações feministas que sinalizam um processo de luta das mulheres pelo direito à cidade e, mais amplamente, pelo direito ao próprio corpo e à vida. Essa luta se dá em atos, manifestações, mas também nos pequenos gestos da ação silenciosa de mulheres em seu cotidiano. Contra as formas sutis e simbólicas de violência institucionalizada e contra a própria banalização da vida das mulheres, as lutas feministas revelam um movimento social não hierárquico, transescalar e que tem crescido expressivamente nos últimos anos.

Ciente de que há um vasto campo de abordagens possíveis para o tema e que essa discussão não será aqui esgotada, o caminho escolhido passa pela identificação de ações

1 MC Carol Feat Heavy Baile. Marielle presente. Niterói, 2018. Disponível em: $<$ https://www.youtube.com/watch?time_continue=4\&v=iPoHMYfxDoQ>. 
que apontam para a natureza política do feminismo e que evidenciam o debate público de temas tratados como demandas específicas de uma minoria, quando são relativas, pelo menos, à metade da humanidade. A crítica à ciência tem sido pontuada pelas agendas feministas e tem resultado em novas epistemologias.

Há cerca de três décadas, geógrafas/os e urbanistas têm se dedicado à questão urbana numa perspectiva feminista. Mais recentemente, uma abordagem feminista passou a ser mais expressiva nos estudos urbanos da América Latina e, na ciência geográfica, o Brasil tem se destacado. O debate sobre o espaço e gênero tem ampliado sua importância na Geografia, com publicações relevantes, congressos em âmbito internacional e em rede de pesquisas dedicadas ao tema, como a Rede de Estudos de Geografia e Gênero da América Latina (REGGAL). Ainda hoje consideradas geografias subversivas (SILVA, 2009), as geografias feministas existem e resistem aos preconceitos e apagamentos alheios às suas reflexões. Esta produção dedica-se ao tema do corpo e, para Silva, na "Geografia, as vertentes que realizaram esforços em problematizar a relação entre corpo e espaço foram as feministas, queer, nova geografia cultural e a fenomenologia" (SILVA, 2013, p. 30).

O processo de institucionalização do controle estatal sobre o corpo feminino é algo que precisa ser enfatizado nestes estudos para que se possa evidenciar como é profunda e dolorida a ferida do machismo na vida social, especialmente em sociedades marcadas pelo colonialismo, pelo patriarcalismo e pela escravidão. Na mesma direção, a reflexão aponta para o modo como a ciência é fortemente afetada pelo machismo institucional, revelando a necessidade de uma epistemologia feminista para que o pensamento possa se movimentar de modo a acompanhar o movimento da sociedade em sua totalidade.

A fim de apresentar a proposta teórico-metodológica que orienta a reflexão e, diante desta abrangente temática permitida pelo tema geral da pesquisa, o artigo se organiza em duas partes: uma primeira em que se destaca uma crítica feminista ao fazer científico dominante e a importância de uma epistemologia feminista para um projeto de ciência capaz de enfrentar e superar o machismo institucional; e a segunda parte do texto, que se dedica à análise da ação feminista na cidade e às lutas pelo direito à vida das 
mulheres. Dedicando especial atenção à conjuntura política destas ações que marcam a vida urbana com suas proposições e disputas de sentido, é possível reconhecer avanços e retrocessos na conquista de direitos e políticas públicas destinadas às mulheres.

\section{Feminismo plural e epistemologias em disputa}

A proposta de investigar a luta pelo direito à cidade numa perspectiva feminista problematizando os pressupostos epistemológicos de uma ciência branca, masculina e ocidental, visa permitir a emergência de outros saberes, plurais e historicamente invisibilizados, subalternizados e desqualificados enquanto conhecimento. A mudança radical dos lugares de enunciação surge como um caminho para evidenciar que a ciência é uma construção social que pode e deve ser debatida e questionada. Por essa razão, a orientação teórico-metodológica da presente pesquisa passa pela valorização da subjetividade, da posicionalidade e das formas de resistência à colonialidade do saber.

Considera-se fundamental o conhecimento acumulado na experiência cotidiana de grupos sociais e movimentos da sociedade que vão para além do conhecimento científico, sem, contudo, desconsiderar a importância da incorporação crítica de conceitos e métodos de pesquisa frequentemente acionados na academia. Donna Haraway (1995) ressalta o valor dos saberes situados, corporificados, parciais, localizados, críticos, que formem redes de conexões e articulem a política e a epistemologia. As autoras e autores com os quais o texto dialoga demonstram ter compromisso com o pensamento crítico, seja no fazer científico ou na vida social em geral. Em alguns casos, assumem sua posicionalidade diante dos temas pesquisados e seus envolvimentos com movimentos de resistência e insurgência a que se dedicam. 
Algumas referências teóricas indicam o caráter coletivo do fazer científico e a necessária reflexividade da análise para a compreensão da vida urbana. O diálogo profundo com a Sociologia do Presente (RIBEIRO, 2013) e com as Teorias da Ação (RIBEIRO, 2014), de Ana Clara Torres Ribeiro, pautado na consolidação de uma episteme dialógica, sensível e criativa no planejamento urbano, e para além dele, muito nos tem inspirado (OLIVEIRA, 2012). Suas reflexões sobre o sujeito corporificado, que se transforma em acontecimento, onde e quando são esperados o seu silêncio e apagamento e que em sua ação cotidiana se opõe aos modelos de cidade (e de urbanidade) excludente (RIBEIRO, 2013), são fundamentais à análise em curso.

Entre as referências bibliográficas da pesquisa, destacamos a valiosa contribuição de Vandana Shiva sobre o Ecofeminismo (1997) e sobre a superação da monocultura da mente no domínio da ciência ocidental (2003). Para Shiva, a sabedoria feminina questiona a revolução científica dos séculos XV e XVI como parte de um sistema dominante que emergiu como projeção ocidental, de orientação masculina e patriarcal, que necessariamente subjuga a natureza e a mulher. Para a autora, a desvalorização dos contributos das mulheres e da natureza caminha de mãos dadas com a mundovisão cartesiana, com os valores atribuídos aos atos de colonização e com o modelo monocultural de desenvolvimento, que vem dominando gradual, mas irreversivelmente, tanto a esfera da produção em escala global, quanto o próprio pensamento humano. Assim, a reflexão sobre as possibilidades de superação de uma ciência culturalmente colonizada que levou à negação de saberes não hegemônicos, vistos como "irracionais", "primitivos", "anticientíficos" e frequentemente desqualificados frente à lógica monocultural, pauta-se na superação da visão reducionista da tradição da "revolução científica", controladas pelo modelo de mundo designado pelo patriarcado capitalista e que a autora sintetiza na ideia de monoculturas da mente a serem combatidas pelo Ecofeminismo.

A perspectiva eurocêntrica, que inferioriza saberes e grupos sociais colonizados, é questionada também pelos autores que se associam ao pensamento decolonial. Autores como Anibal Quijano (2005) e muitos outros da periferia do capitalismo têm evidenciado os modos como a colonialidade do poder e do saber são prejudiciais ao pensamento 
crítico e ao fazer científico. A objetivação do corpo e da natureza revelam como o processo de subjetivação eurocêntrica afeta as relações cotidianas e a produção do conhecimento de modo profundo. Prejudicial à escrita da história (CERTEAU, 1982), à filosofia e, também, aos modos de geo-grafar o mundo (PORTO-GONÇALVES, 2001) a colonialidade do poder precisa ser superada.

O pensamento decolonial sugere um diálogo mais frequente, profundo e fecundo com grupos sociais historicamente subalternizados. Movimentos sociais, ativistas, além de grupos latino-americanos têm feito uma importante aproximação no sentido de criticar a modernidade colonial e revelar formas dissidentes e desobedientes em relação à episteme universal e supostamente objetiva. A crítica e a resistência à colonialidade do saber se referem aos modos de superar a subalternização, folclorização e invisibilização de uma multiplicidade de conhecimentos que não correspondem às modalidades de produção do "conhecimento ocidental” associados à ciência convencional ou ao discurso especializado (MORAES et al., 2013).

Catherine Walsh (2009, p. 15-16) ressalta o sentido do uso do termo "decolonial", suprimindo o "s" para marcar uma distinção com o significado de descolonizar em seu sentido clássico. Destaca que a intenção não é desfazer o colonial ou revertê-lo, ou seja, superar o momento colonial pelo momento pós-colonial. A intenção é provocar um posicionamento - uma postura e atitude contínua - de transgredir, intervir, insurgir e incidir. O decolonial implica, portanto, uma luta contínua (WALSH, 2009, p. 14-15). Sua proposta articula o político e o pedagógico com "[...] um sentido prático e concreto em favor das lutas de descolonização, libertação e humanização" (WALSH, 2013, p. 42) e seu objetivo é "“[...] atacar as condições ontológicas-existenciais e de classificação racial e de gênero; incidir e intervir em, interromper, transgredir, desencaixar e transformá-las de maneira que superem ou desfaçam as categorias identitárias [...]” (WALSH, 2013, p. 55).

Tal como aponta Castañeda (2013), a modernidade foi/é indispensável para a conquista, colonização e dominação da América e seus habitantes, através de uma outridade em relação à Europa. A autora ressalta que o pensamento decolonial possui uma ampla agenda que inclui perguntas sobre como envolver a perspectiva de gênero e 
das mulheres, vincular as discussões sobre dominação da natureza e indagar sobre a possibilidade de pensamentos outros (que não são o pensamento “do outro”).

Para aprofundar a reflexão sobre como o pensamento decolonial tem dado importantes contribuições para a ciência e a sociedade em geral é preciso superar a episteme colonial (masculina, branca, heterossexual, cristã) e subverter de modo provocativo a monocultura da ciência ocidental, inclusive superando a colonialidade expressa nas relações de gênero. Para esse desafio, nos serviu de inspiração a reflexão de Maria Lugones (2014) sobre a opressão de gênero racializada capitalista que a autora chama de 'colonialidade de gênero', ressaltando que o próprio conceito de gênero é uma imposição colonial e que descolonizar o gênero é necessariamente uma práxis. Pensar um feminismo decolonial é considerar a importância da interseccionalidade para a compreensão do feminismo periférico e pensar a posição periférica das mulheres em diversos aspectos com relação à dominação masculina, inclusive na ciência.

Angela Davis, militante dos Panteras Negras e do Partido Comunista dos Estados Unidos, autora do livro "Mulheres, raça e classe", revelava em 1981, como o racismo permanecia presente no movimento feminista e a razão de um sentido radical da noção de emancipação para mulheres negras, desumanizadas pela sociedade escravocrata. Davis é uma referência para pensar um feminismo plural, pois além de destacar a necessidade de garantir a centralidade da mulher negra numa outra construção da noção de feminilidade, descontrói o mito da feminilidade que gira em torno da mulher branca, frágil, delicada e do lar. Na escravidão, as mulheres negras eram submetidas às mesmas condições de trabalho forçado que os homens negros escravizados, sendo delas exigida força equivalente. A principal diferença com relação aos homens negros escravizados era o fato de o corpo das mulheres negras ser constantemente violado pelo estupro. Para Davis (2016), a postura dos senhores em relação às escravas era regida pela conveniência: as exploravam como se fossem desprovidas de gênero e, ao mesmo tempo, poderiam ser reduzidas à sua condição de fêmea para serem ainda mais exploradas, reprimidas e punidas. Quando o tráfico internacional de mão de obra escrava começou a ser ameaçado, a classe proprietária de escravos passou a contar com a reprodução natural como método para repor e ampliar a população de escravas e escravos domésticos. 
Neste sentido, a exaltação ideológica da maternidade - tão popular no século XIX - não se estendia às mulheres escravizadas. Aos olhos de seus proprietários não eram sequer mães, mas instrumentos da ampliação da força de trabalho escrava (DAVIS, 2016).

Considerar esses fatos significa dizer que a proposta desta análise não é tratar a mulher como um sujeito universal, como ocorre em muitas pesquisas que seguem os padrões científicos dominantes. É preciso tentar escapar das formas dominantes de produção do conhecimento que se universalizaram se quisermos caminhar numa abordagem feminista decolonial. A pluriversalidade, portanto, mais do que uma intenção, é a orientação possível em um mundo repleto de diferenças e especificidades. A contribuição do feminismo plural (movimentos como os das mulheres negras, indígenas, trans) tem implicado em mudanças nos conceitos e na afirmação de posicionamentos que provocaram mudanças na ação feminista em geral. A abordagem pluriversa e interseccional é desafiadora porque permite o alcance de camadas sobrepostas de estigmatização, disciplinarização e submissão, mas também o alcance e o desvendamento das formas de insubordinação, antidisciplina e resistência.

Para Silvia Federici (2017), a reconstrução da história das mulheres, ou o olhar sobre a história por um ponto de vista feminino, exige uma redefinição das categorias históricas aceitas e uma visibilização maior das estruturas ocultas de dominação e exploração. Federici (2017) destaca a contribuição de Marx para o entendimento do capitalismo ao conceber a alienação do corpo como um traço distintivo da relação entre capitalista e trabalhador. A transformação do trabalho em mercadoria pelo capitalismo faz com que os trabalhadores subordinem sua atividade a uma ordem externa sobre a qual não têm controle e com a qual não podem se identificar. Entretanto, a autora ressalta que Marx não observou que o desenvolvimento das potências industriais se deu à custa do subdesenvolvimento dos trabalhadores enquanto indivíduos sociais e, principalmente, desconsiderou que "longe de ser um resquício pré-capitalista, o trabalho doméstico não remunerado das mulheres tem sido um dos principais pilares da produção capitalista, ao ser o trabalho que produz a força de trabalho" (FEDERICI, 2017, p. 11).

Federici argumenta que a subordinação das mulheres aos homens no capitalismo foi causada pela não remuneração, e não pela natureza "improdutiva" do trabalho 
doméstico, e que a dominação masculina é baseada no poder que o salário confere aos homens (FEDERICl, 2017). A expulsão das mulheres do espaço de trabalho organizado, assim como a proibição de práticas relacionadas aos saberes ancestrais (das curandeiras, parteiras) ou mesmo da prostituição, estiveram diretamente relacionadas à restrição das mulheres à condição de trabalhadoras não assalariadas no lar.

Para Federici (2017), Marx ignorou a importância do trabalho das mulheres nas atividades diárias que sustentam a reprodução da força de trabalho e a preparação de bens de consumo, negligenciando também o fato de produtos como açúcar, café e algodão serem produzidos pelo trabalho escravo empregado, por exemplo, nas plantações de cana brasileiras. Observando o desenvolvimento capitalista do ponto de vista dos não assalariados - que trabalham nas cozinhas e nas plantações, fora de relações contratuais, cuja exploração foi naturalizada, creditada a uma inferioridade natural -, o livro Calibã e a bruxa, de Federici (2017) afirma a total impossibilidade de qualquer "troca igualitária" dentro do capitalismo, que enquanto sistema econômicosocial está necessariamente ligado ao racismo e ao sexismo.

O capitalismo combinou a feminização da pobreza, pela desvalorização da posição social das mulheres pela não remuneração do seu trabalho (seja o doméstico ou no campo) com o controle estatal sobre seus corpos. Corpos femininos ou que carreguem as marcas da feminilidade, sobremarcados por raça, classe, religião, orientação sexual, idade, lugar de nascimento ou moradia (RODRIGUES, 2018) são as vítimas mais frequentes da violência de uma sociedade misógina.

Como exemplificação do controle sobre o corpo feminino tem-se a mecanização do corpo proletário e sua transformação, no caso das mulheres, em uma máquina de produção de novos trabalhadores. Quando se considerou favorável ao capital ter altas taxas de natalidade, o útero foi reduzido a uma máquina nas mãos do Estado e dos médicos e desse movimento surge a condenação do aborto e da contracepção. No contexto dessa condenação, a perseguição às bruxas e àquelas que detinham conhecimento do funcionamento do corpo foi o ponto de culminância da guerra contra as mulheres. Para Federici, essa batalha contra o corpo, que caracterizou os primórdios do desenvolvimento capitalista continua, de diversas formas, até nossos dias. 
Na história dessa tentativa de controle do corpo pelo Estado, o fenômeno da caça às bruxas se atualiza, não se restringindo à Inquisição ou ao período colonial. Tal como o Coletivo Sycorax aponta na tradução do livro de Federici, o encarceramento massivo de mulheres negras perpetrado pelo Estado; a sub-representação ou representação deturpada da mulher nos meios de comunicação; as violências obstétricas contra as cidadãs que recorrem ao Sistema Único de Saúde (SUS); os corpos das vítimas da violência policial nas periferias; e a experiência cotidiana de perseguição, silenciamento, agressão e invisibilização das mulheres trans, travestis e prostitutas, entre tantos outros casos, revelam a atualidade das formas de violência contra as mulheres.

O feminismo pode ser entendido como constituição histórica da resistência das mulheres à dominação sobre os corpos. Os exemplos da insubordinação de mulheres são muitos e seculares, como de mulheres que nas Américas chegaram a ser consideradas as principais inimigas do domínio colonial (FEDERICI, 2017, p. 402) ou das mulheres negras que muito antes do feminismo europeu já se mostravam insubordináveis, como nos revela a figura de Sojourner Truth (1797-1883), nome adotado por Isabella Baumfree. Nascida no cativeiro em Swartekill, Nova York, Truth conquistou a própria liberdade em 1827 e tornou-se uma abolicionista afro-americana ativista dos direitos da mulher. "Ain't I A Woman?" (em português: "Eu não sou uma mulher?") foi o nome dado ao discurso da ex-escrava na Women's Convention em Akron, Ohio, em 1851, e que a tornou conhecida pela contundência com que questionou as mulheres brancas que não consideravam a realidade vivida pelas negras ${ }^{2}$.

Para Federici (2017, p.32) uma das contribuições dos estudos feministas dos anos 1970 é a compreensão dos modos de disciplinarização e de apropriação do corpo feminino ainda que sem aprofundar que essa era a compreensão possível estando a pesquisadora situada em lugar e em um tempo específico. A autora destaca ainda a errônea percepção, tão frequente entre os acadêmicos, que atribui a discussão da disciplinarização do corpo quase exclusivamente a Michel Foucault quando, partindo de uma análise da "política do corpo", as feministas já haviam revolucionado o discurso

\footnotetext{
${ }^{2}$ GELEDES. Sojourner Truth. Publicado em: 23 mai. 2009. Disponível em: <https://www.geledes.org.br/sojourner-truth/>. Acesso em: 20 jul.2018.
} 
filosófico e político e passado a revalorizar análises corporificadas. Para Federici, o que Foucault teria aprendido, caso tivesse estudado em sua História da sexualidade (1978) a caça às bruxas, em vez de ter se concentrado na confissão pastoral, é que essa história não pode ser escrita do ponto de vista de um sujeito universal, abstrato, assexuado (FEDERICI, 2017, p. 36). É, portanto, merecida a importância que adquiriu o corpo, em todos os seus aspectos - maternidade, parto, sexualidade, exploração —, tanto na teoria feminista quanto na história das mulheres.

A importância do conceito de corpo nos estudos feministas está no fato de que ser mulher é ter o corpo em evidente controle externo. O controle sobre os corpos femininos é algo que se desenha historicamente junto com um projeto de dominação mais amplo: uma tentativa do Estado e da Igreja de transformar as potencialidades dos indivíduos em força de trabalho, tal como revela Federici (2017) ao analisar como o capitalismo enfrentou as mulheres, em diferentes momentos históricos. Dentre os sujeitos femininos que o capitalismo precisou destruir, Federici ressalta a herege, a curandeira, a esposa desobediente, a mulher que ousa viver só, a mulher de língua afiada, a que envenenava a comida do senhor e incitava os escravos à rebelião, entre outras insubordináveis.

A respeito das formas de institucionalização do controle sobre o corpo feminino, o controle sobre a fertilidade/fecundidade feminina é uma das mais evidentes expressões de um projeto de poder, em que o controle estatal (institucional) sobre os corpos das mulheres passa pelo controle dos corpos subalternizados. Na análise feita por Federici (2017), foram os efeitos da intervenção estatal contra o corpo proletário na era moderna e de uma "caça às bruxas" que provocaram (e ainda provocam) uma subalternização das mulheres.

A corporificação é relevante para as práticas espaciais e, do mesmo modo, relevante para a execução de pesquisas (SILVA, 2017). Para Silva, a luta feminista em torno do direito ao corpo-espaço envolve questões como sexualidade, aborto, gravidez e o medo da violência. O corpo é a condição de existência da força de trabalho, mas é também seu limite, já que constitui o principal elemento de resistência à sua utilização e objetificação. 
Assim, se o feminismo é toda luta de mulheres que se opõem ao patriarcalismo ${ }^{3}$, e se não desejamos universalizar a figura da mulher, teríamos que construir sua genealogia considerando a história de muitas mulheres em muitos espaços-tempos, tal como sugere Curiel (2009).

A epistemologia feminista é uma teoria crítica sobre o conhecimento e uma busca para a superação de contextos acadêmicos sexistas. Por subverter pressupostos iluministas, como a crença na neutralidade e numa objetividade que desqualifica a subjetividade, exige uma reflexão sobre a posicionalidade. Para Silva, Ornat e Chimin Junior (2017), posicionalidade é uma noção que nos ajuda a entender as influências da teoria feminista na produção geográfica de Doreen Massey. Segundo os autores (2017), ser uma geógrafa feminista, para Doreen Massey, implicava pensar o conhecimento, as relações políticas e de poder que eram inerentes ao processo de constituição da imaginação geográfica e de seu processo de legitimação, e não apenas dedicar-se aos estudos de gênero. Um exemplo dado pelos autores é o texto Flexible Sexism em que Doreen Massey (1991b) faz críticas a David Harvey (1989) e Edward Soja (1989) em seus respectivos textos, Condição Pós-moderna e Geografias pós-modernas, pelo fato dos autores terem se comprometido a discutir modernidade/pós-modernidade na Geografia, com análises sexistas que desconsideraram uma literatura produzida anteriormente pelas feministas. Para Massey, a crítica a Harvey e a Soja está no fato de os autores terem assumido a universalidade de subjetividades e processos sociais quando os sujeitos apresentados por suas análises são descorporificados em termos de raça e gênero. Sendo assim, os autores assumem um sujeito genérico, que é, objetivamente, ocidental,

3 Para Berner e Melino (2016), seria mais adequado falar em patriarcalismo do que em "patriarcado", já que este afetaria apenas a um determinado coletivo (a mulher em abstrato), ao passo que o "patriarcalismo" é a categoria que abrange o conjunto de relações que articulam um conjunto de opressões indiferenciado: gênero, sexo, etnia e classe social, bem como o modo como as relações sociais particulares conjugam uma dimensão pública de poder, exploração ou a servidão pessoal. Para as autoras, o termo patriarcalismo, entendido como a base e suporte de todo tipo de dominação autoritária ou totalitária parece mais adequado, pois nos faz ver como as relações patriarcais se articulam com outras formas de relação social em um dado momento histórico. Isto porque as estruturas de classe, racismo, gênero e sexualidade não podem ser tratadas como variáveis independentes, pois a opressão de cada uma está insculpida na outra (BERNER e MELINO, 2016, p. 1871). 
masculino, branco e heterossexual como modelo para a generalização de suas teorias e a ausência dos sujeitos que não são protagonistas da modernidade seria fator limitador da análise.

Na análise de Silva, Ornat e Chimin Junior (2017), Massey denuncia que as referidas obras de Harvey e Soja apresentam como 'descobertas' ou 'novidades' aspectos que já haviam sido antecipados na literatura feminista, como a ideia do conhecimento situado já trabalhada por Haraway (1988 apud SILVA, ORNAT E CHIMIN JUNIOR, 2017). Segundo Massey, a ignorância desses autores sobre elementos que não eram mais novidades está baseada na sua desconsideração das vozes femininas na produção científica e sua crítica aos autores aparece ainda no modo simplista como as relações de poder e políticas são tratadas apenas em torno do capitalismo, deixando de lado outras importantes dinâmicas de sexismo, racismo e homofobia, reduzindo tais processos a simples efeitos secundários do sistema capitalista. Doreen Massey entende que a historicidade linear adotada pelos autores impede a emergência de outras vozes e contradições que devem ser analisadas como componentes dos processos de produção e reprodução social. Neste sentido, destacamos uma vez mais as especificidades das lutas feministas pelo direito à cidade.

Mulheres negras, da periferia, indígenas, do campo, homoafetivas ou transexuais indicam a pluralidade das sujeitas e suas variadas demandas e demonstram a interseccionalidade necessária às abordagens de gênero ${ }^{4}$. A ação de mulheres negras, indígenas, assim como o transfeminismo são expressões de como a interseccionalidade é imprescindível à compreensão dos movimentos com os quais estamos refletindo.

\section{O direito à cidade numa perspectiva feminista}

Houve, nas últimas décadas, um crescimento da ação das mulheres em busca de igualdade de oportunidades, da criação de organismos públicos voltados à defesa e da

\footnotetext{
4 Interseccionalidade é um conceito cunhado por Kimberlé Williams Crenshaw que busca evidenciar a sobreposição de múltiplos sistemas de subordinação, como a opressão de classe, o racismo, o patriarcalismo e outros sistemas discriminatórios de modo a compreender as consequências estruturais, dinâmicas e complexas da associação das relações de gênero, étnicoraciais, de classes, entre outras.
} 
ampliação dos direitos das mulheres no país. Mas ainda é preciso avançar muito. Nas lutas por direitos, mulheres sentem que a cidade e o desenho urbano favorecem a reprodução da cultura do machismo. Ao circularem pela cidade, as mulheres encontram limites relacionados aos horários e lugares onde podem estar seguras da violência sobre seus corpos. Sendo a cidade majoritariamente produto da ação de homens, as decisões relativas aos transportes são emblemáticas dessa concepção patriarcal de cidade, justamente por ser um dos setores mais interditados à participação feminina.

Como se sabe, o referencial técnico de transportes e mobilidade é centrado na velocidade e os custos sociais do padrão rodoviarista são visíveis na metrópole. Qualquer tentativa de diminuir a presença de carros (como o apoio ao uso da bicicleta), ou mesmo de redução dos limites máximos de velocidade em autopistas, parece atingir em cheio a essa cultura da "aceleração desenfreada", da competitividade a ela relacionada e, talvez até a própria masculinidade construída com base nestes mesmos signos de competitividade e brutalidade que se vê no trânsito da cidade.

Um planejamento urbano pautado pela diversidade da vida social deveria garantir amplo acesso a políticas e equipamentos urbanos, promovendo usos coletivos e o convívio das diferenças. Deveria ainda priorizar as pessoas e suas eventuais condições de vulnerabilidade e não apenas a produção e circulação de mercadorias, como se concebe na cidade capitalista. É preciso considerar que a vivência urbana é radicalmente diferente para homens e mulheres e muito mais difícil para as mulheres negras, trans e/ou habitantes das periferias, que são as que mais frequentemente sofrem os impactos deste padrão de urbanização excludente e patriarcal ${ }^{5}$. Mulheres foram historicamente responsabilizadas pelo cuidado e pelos afazeres domésticos. São as que circulam com crianças, com pessoas portadoras de deficiências, doentes e idosos e transitam por cidades nada acessíveis ou amigáveis.

\footnotetext{
${ }^{5}$ Debate "Feminismo e planejamento urbano: Construindo pontes" aborda o papel das mulheres na construção das cidades", 16 Jun 2016. ArchDaily Brasil. Acessado em 30 Mar 2018. <https://www.archdaily.com.br/br/789633/debate-feminismo-e-planejamento-urbanoconstruindo-pontes-aborda-o-papel-das-mulheres-na-construcao-das-cidades $>$. ISSN 0719-8906
} 
O movimento feminista, entendido de modo amplo em sua pluralidade e diversidade como movimentos das mulheres contra as imposições da cultura do machismo, revela a complexidade de sua ação e a amplitude de abordagens possíveis. Para Angela Davis, um novo movimento feminista internacional - ao mesmo tempo antiracista, anti-imperialista, anti-heterossexista e anti-neoliberal está em andamento ${ }^{6}$. Em termos gerais, a luta contra os altos índices de feminicídio continua sendo a maior evidência da necessidade das mulheres se organizarem para traçar táticas de sobrevivência no cenário hostil que a vida social representa.

No Brasil, avanços importantes como a Lei $n^{\circ} 11.340 / 2006$, conhecida como Lei Maria da Penha, que torna crime a violência contra as mulheres e mudanças do Código Penal, como a Lei $n^{\circ}$ 12.015/2009, que trata dos crimes contra a dignidade sexual, e como a Lei $n^{\circ} 13.104 / 2015$, que classifica o feminicídio como circunstância qualificadora do crime de homicídio merecem ser destacados. Instituições especializadas no atendimento de mulheres expostas a alguma situação de violência, como Núcleos de Atendimento à Mulher (NUAM), em delegacias distritais, e as Delegacias Especializadas de Atendimento à Mulher (DEAM) também podem sinalizar uma pequena conquista das lutas feministas, embora em 2014 apenas 7,9\% dos municípios brasileiros contassem com delegacia de atendimento à mulher. Dados do Mapa da Violência de 2015 mostram que, só em 2013, 13 brasileiras morreram por dia vítimas de feminicídio, ou seja, apenas por serem mulheres.

Mas é preciso avançar mais diante dos retrocessos legais a que estão submetidos os corpos femininos. O homicídio de mulheres negras aumentou $22 \%$, ao passo que o das brancas caiu 7,4\% em 2017, de acordo com os dados divulgados pelo IPEA no Atlas da Violência 2017. Um balanço da Central de Atendimento à Mulher - Ligue 180, de 2015, constatou que $59,71 \%$ das vítimas de violência doméstica são negras. O aumento do número de mulheres encarceradas no Brasil é alarmante, passando de 6,5 para 36,4 a cada 100 mil, de 2000 a 2014. "O Ministério da Justiça estima que duas em cada três sejam negras e cometeram crimes não violentos, usualmente sob ordens de alguém, como o

\footnotetext{
${ }^{6}$ Angela Davis é uma das autoras do texto que convoca uma greve geral internacional das mulheres. Por uma greve internacional militante no dia 8 de março. Disponível em: $<$ https://blogdaboitempo.com.br/2017/02/07/por-uma-greve-internacional-militante-no-8-demarco/>.
} 
companheiro" (CARASCO e CORTÊS, 2018) ${ }^{7}$. Estas mulheres negras e pobres também são impactadas pela violência racial que mata ou prende seus filhos, maridos, sobrinhos e netos (idem).

O assédio de rua é outro tormento na vida da maioria das mulheres, como revelou a campanha "Chega de fiu-fiu" ${ }^{8}$, uma tentativa de denunciar e mapear os lugares mais incômodos e até perigosos para mulheres no Brasil por meio de depoimentos no site e mapeamento interativo. O medo é o sentimento predominante entre as mulheres que relatam casos de abusos e buscam formas horizontais e solidárias de organização e defesa.

Para tratamos dos direitos relativos à educação e das oportunidades educacionais para mulheres é preciso incluir a luta por creches em horários e locais que possibilitem à mulher maior agilidade em seus percursos cotidianos pela cidade e uma melhor inserção no mercado de trabalho; a luta por creches em instituições de ensino, como nas universidades públicas, de modo a garantir a permanência de estudantes mães no ensino superior, sua qualificação profissional e o devido cuidado e atenção aos bebês. Mas é sempre importante considerar as condições diferenciadas e desiguais de acesso à educação, especialmente no caso do ensino superior, e mais ainda quando relacionamos os dados relativos ao gênero com os por raça/cor. Na população de 25 anos ou mais de idade com ensino superior completo, as mulheres brancas são $23,5 \%$, seguidas pelos homens brancos, com 20,7\%; bem abaixo estão as mulheres pretas ou pardas, com 10,4\% e, por fim, os homens pretos ou pardos, com 7,0\%.

7 CARASCO, Daniela e CORTÊS, Natacha. Ser mulher no Brasil machuca: Políticas públicas deficientes e estatísticas cruéis escancaram um país omisso com a vida de suas mulheres. Publicado em 08 de março de 2018. Reportagem: Daniela Carasco e Natacha Cortêz; Edição: Vladimir Maluf; Direção de Arte: Mariana Romani; llustrações: Priscila Barbosa. Acessado em 30 mar 2018. Disponível em: <https://universa.uol.com.br/especiais/ser-mulher-nobrasil-machuca/index.htm?utm_source=facebook.com\&utm_medium=social\&utm_campaign=fbestilo\&utm_content=geral\#ser-mulher-negra-no-brasil-e-estar-a-margem-da-sociedade $>$.

${ }^{8}$ Para tentar entender melhor o assédio sexual em locais públicos, a página Think Olga contribuiu para a realização de uma pesquisa elaborada pela jornalista Karin Hueck, como parte da campanha Chega de Fiu Fiu. Foram 7762 participantes e 99,6\% delas afirmaram que já foram assediadas - um número tão alto que já dá a ideia da gravidade do problema. Pesquisa completa em: <https://olga-project.herokuapp.com/2013/o9/og/chega-de-fiu-fiu-resultado-da-pesquisa/>. 
No Brasil, das 10,3 milhões de crianças de zero a quatro anos, apenas 25,6\% estão matriculadas em creches ou escola. Na Pesquisa Nacional por Amostra de Domicílios (PNAD), de 2015, o IBGE perguntou aos responsáveis pelas crianças que estão fora das creches se havia interesse na matrícula: a resposta foi positiva para $61,8 \%$ dos entrevistados, o equivalente a 4,7 milhões de crianças. O instituto, no entanto, não se aprofundou na análise dos motivos que levaram à baixa frequência na pré-escola. A evasão escolar por conta da maternidade precoce afasta da escola mais de 300 mil mães adolescente, segundo dados da mesma pesquisa em 2013.

No campo da saúde, a luta das mulheres, inclui a defesa do Sistema Único de Saúde - SUS - e de políticas de saúde específicas para as mulheres; contra as violências médicas, como a violência obstétrica; em defesa da humanização do parto e contra a restrição de direitos das mulheres e das profissionais (doulas, parteiras, obstetrizes que auxiliam partos domiciliares ou que participam de equipes de retaguarda e assistência à gestante); e pelo direito à livre amamentação (com políticas de apoio ao aleitamento materno) que vão desde a ampliação de direitos trabalhistas à adequação do mobiliário urbano (público e privado) para a oferta de condições adequadas para o aleitamento; e a luta contra a criminalização do aborto e pela legalização de formas seguras e gratuitas de interrupção da gestação.

Dados do Ministério da Saúde indicam que a cada dois dias, uma brasileira pobre

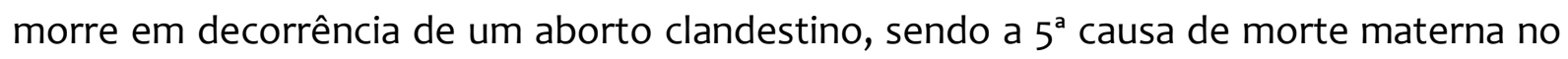
país. Aos quarenta anos, uma em cada cinco brasileiras, já abortou, tal como mostrou o mais recente estudo sobre o tema, a Pesquisa Nacional do Aborto (PNA), feito pela Anis Instituto de Bioética e pela Universidade de Brasília (UnB) e divulgado na revista Ciência e Saúde Coletiva, que entrevistou 2.002 mulheres entre 18 e 39 (DINIZ; MEDEIROS e MADEIRO, 2017). Uma em cada cinco delas já fez, pelo menos, um aborto na vida. Em 2015, 1.300 mulheres arriscaram a vida para interromper, ilegalmente, uma gravidez, no Brasil, o que faz do aborto uma questão de direitos humanos e de saúde pública.

Ao tentar constranger a mulher e dificultar a denúncia do crime de estupro, projetos de lei e propostas de emendas constitucionais seguem retirando direitos conquistados pelas mulheres vítimas de violência sexual e criminalizando quem apoie 
alguma mulher em situação de abortamento. As propostas incluem criminalização da vítima de violência sexual, que terá que provar que sofreu o crime e perderá a garantia do fornecimento da pílula do dia seguinte, além de não ser mais informada sobre seus direitos legais e sobre os serviços sanitários disponíveis. Somando-se aos projetos de leis que dificultam o acesso das vítimas de abuso sexual a atendimentos de saúde, o evidente retrocesso quanto aos direitos sexuais e reprodutivos das mulheres parece ganhar apoio no poder executivo, sobretudo com a recente perda de status de Ministério da Secretaria Especial de Políticas para as Mulheres, do governo federal ${ }^{9}$.

Questões imprescindíveis como o debate sobre aborto e esterilização feminina passam ao largo dos departamentos responsáveis pela elaboração de políticas públicas porque, em última instância, contrariam a ordem cultural que reduz a mulher à figura da mãe e à lógica reprodutiva controlada pelo Estado. Se tal concepção do Estado controlando os corpos femininos e pautada numa lógica machista e sexista afeta especialmente as mulheres negras e pobres, afeta ainda mais as políticas de atendimento às mulheres transexuais, que permanecem dependendo do sistema de saúde e resistindo na luta diária por atendimento digno, amplo e respeitoso de sua condição e identidade. Tal como afirma Raquel Oscar, "mais uma vez se perde a oportunidade de romper com as estruturas simbólicas e materiais que hierarquizam os gêneros" (OSCAR, 2016). Ainda de acordo com a autora, ao assumir que as políticas públicas podem transformar o cenário cultural do país, é preciso compreender que o sujeito feminino é um "ser social” dotado

\footnotetext{
${ }^{9}$ A reportagem “No governo Temer, Secretaria das Mulheres ganha viés policial”, de Debora Melo, publicada em 04/06/2016, na versão digital da revista Carta Capital, os retrocessos feitos pelo governo de Michel Temer são destacados. De acordo com a reportagem, "quando subordinou a Secretaria Nacional das Mulheres ao Ministério da Justiça e da Cidadania" o governo interino sinalizou um enorme retrocesso quanto aos direitos sexuais e reprodutivos das mulheres e ainda, ao nomear uma representante da bancada evangélica para a pasta, apontou para a aprovação de pautas como o Estatuto do Nascituro que garante direitos ao feto e reduz o apoio às mulheres vítimas de estupro. Na reportagem, a deputada federal Maria do Rosário (PT-RS) afirma que a base de sustentação de Temer no Congresso "nasce do conservadorismo, do controle sobre o corpo feminino e da própriacultura do estupro". Disponível em: $<$ http://www.cartacapital.com.br/politica/sob-temer-fatima-pelaes-da-vies-policial-a-politicas-paramulheres $>$. Último acesso em: 30/03/2018.
} 
de agência política, entendendo que as relações desiguais nas quais se encontram foram historicamente construídas e, portanto, são passíveis de modificação.

"Papéis de gênero" são construções sociais e não verdades naturais e absolutas, portanto não devem limitar as pessoas, homens ou mulheres, ou ainda permitir que uma determinada identidade de gênero seja causa de violência, discriminação ou restrição de direitos. Dados sobre o mercado de trabalho mostram que as mulheres não têm as mesmas oportunidades e condições que os homens em diversos aspectos, como rendimento, formalização e disponibilidade de horas para o trabalho remunerado. As mulheres são $92,3 \%$ dos empregados domésticos, sendo que $71,6 \%$ das trabalhadoras domésticas não têm carteira assinada. Os dados atestam que ainda há muito a conquistar na direção da igualdade de gênero, uma vez que mesmo trabalhando, em média, três horas por semana a mais do que os homens, combinando trabalhos remunerados, afazeres domésticos e cuidados de pessoas, e mesmo contando com um nível educacional mais alto, mulheres ganham, em média, $76,5 \%$ do rendimento dos homens ${ }^{10}$. As mulheres vivem situações de segregação ocupacional e discriminação salarial no mercado de trabalho e estão mais vulneráveis às restrições e perdas de direitos trabalhistas, como demonstram as recentes mudanças nas normas de aposentadoria.

Ainda são insuficientes as políticas públicas desenvolvidas especificamente para as mulheres no Brasil. Se o acesso aos espaços de poder não garante às mulheres mudanças significativas na gestão urbana, sem acesso a estes espaços de decisão certamente suas demandas não serão consideradas prioridades. Quando se constata que as cidades se tornaram o que são com as formas de planejamento e gestão urbanas pensados e executados majoritariamente por homens, é de se esperar que a revolução urbana seja feminista e interseccional (anti-racista, anti-homofóbica e não-sociocêntrica), para que, de fato, outros modos de pensar e agir possam ser considerados uma renovação da vida urbana.

\footnotetext{
${ }^{10}$ Informativo Estatísticas de Gênero - Indicadores sociais de mulheres no Brasil, produzido pelo IBGE/CDDI/GEDI.
} 
Nos últimos anos, o movimento feminista vem chamando a atenção por meio de diversas ações político-culturais sobre as quais poderíamos nos dedicar a compreender. Atos como a Marcha Mundial das Mulheres, a Marcha das Vadias, a Marcha das Mulheres Negras, a Marcha das Margaridas e a Greve Mundial de Mulheres têm evidenciado a força do feminismo e parecem ganhar potência frente às pautas machistas, misóginas e conservadoras que avançam no campo da política ${ }^{11}$. Esses atos revelam como as ruas são tomadas pelos encontros, passeatas, ocupações, grafites e outras manifestações políticas ou culturais que indicam a vitalidade dos movimentos de mulheres. As violências cotidianamente sofridas pelas mulheres são um fenômeno histórico, enraizado na sociedade e que, paradoxalmente, revelam as lutas e re-existências vividas cotidianamente.

\footnotetext{
${ }^{11}$ Em 08 de novembro de 2017, a Proposta de Emenda Constitucional (PEC) 181, de 2015, foi votada numa controversa comissão especial montada na Câmara dos Deputados, evidenciando uma ofensiva da chamada "bancada da bíblia" contra os direitos das mulheres. Originalmente propondo a ampliação da licença maternidade para os casos de nascimento prematuro, à PEC 181/2015 foi acrescentado um artigo pelo relator Jorge Tadeu Mudalen (DEM-SP) com uma declarada intenção de trabalhar contra o direito ao aborto. Essa não foi a única iniciativa a sugerir que o aborto deva ser considerado um ato que viola o direito à vida e que por essa razão deveria ser punido pelo Estado com extremo rigor, mesmo sem considerar os riscos à vida da mulher ao tentar impedir ou criminalizar todas as formas de aborto, inclusive em casos de estupro e anencefalia. De acordo com a reportagem "Ofensiva na Câmara para complicar atendimento à vítima de abuso sexual", de Mariana Rossi, publicada na edição brasileira do Jornal El País, em 22 de outubro de 2015, uma série de projetos de lei pretendem dificultar o acesso ao aborto por mulheres vítimas de abuso sexual (como o PL5069/13) e criminalizar a ação de profissionais da saúde que atendem às vítimas. A reportagem revela o protagonismo de Eduardo Cunha na autoria de projetos de lei que revelam a investida moralista contra os direitos das mulheres, citando o projeto de Lei $(\mathrm{PL}) 7443 / 2006$, que dispõe sobre a inclusão do aborto na modalidade de crime hediondo; o PL 1545/2011, que impõe ao médico que praticar o aborto uma pena de prisão que vai de seis a vinte anos; a Proposta de Emenda à Constituição (PEC) 164/2012, que versa sobre a inviolabilidade do direito à vida "desde a concepção", incluindo, portanto, o embrião; e o PL 5069/2013, que passa a considerar crime contra a vida o anúncio de substância ou objeto destinado à interrupção da gravidez e a orientação de gestantes para o procedimento, com pena de até dez anos de reclusão. Disponível em: <http://brasil.elpais.com/brasil/2015/10/23/politica/1445557952_906110.html>. Último acesso em: 12/06/2016.
} 


\section{Considerações finais}

Durante a escrita deste artigo, houve, na cidade do Rio de Janeiro, um brutal assassinato que, infelizmente, serve de evidência de que a luta das mulheres - em especial sendo pretas, oriundas da favela e lésbicas - é uma luta diária. Nascida e criada na favela da Maré, Marielle Franco fez curso pré-vestibular comunitário, tornou-se socióloga sendo bolsista/cotista na PUC/RJ e, no seu mestrado em administração pública na Universidade Federal Fluminense, abordou o tema da segurança pública com a dissertação "UPP: a redução da favela a três letras", revelando o olhar de quem conhece por dento tal realidade. Feminista, militante dos direitos humanos e ativista do movimento LGBT, a vereadora Marielle Franco foi eleita no Rio de Janeiro pelo PSOL (Partido Socialismo e Liberdade), com 46.502 votos e foi Presidente da Comissão da Mulher da Câmara. Saía do evento "Roda de Conversa: Jovens Negras Movendo as Estruturas", quando foi brutalmente morta a tiros, com o motorista Anderson Gomes, a caminho de casa.

Nem todos os crimes têm a mesma carga simbólica e a execução de Marielle teve grande repercussão nacional e internacional, provocando uma comoção traduzida em atos e mobilizações em diversas cidades. Marielle havia assumido dias antes a relatoria da comissão criada na Câmara dos Vereadores para fiscalizar a intervenção militar, com o poder de aprovar relatórios e providências contra militares e policiais. A vereadora havia publicado nas redes sociais graves denúncias contra a atuação da Polícia Militar (PM) na comunidade do Acari, zona norte da cidade do Rio de Janeiro e uma mensagem sua terminava questionando: "Quantos mais vão precisar morrer para que essa guerra acabe?". Em postagem anterior, em 10 de março, Marielle Franco denunciou a ação do $41^{\circ}$ BPM e escreveu: "O que está acontecendo agora em Acari é um absurdo! E acontece desde sempre! $\mathrm{O} 41^{\circ}$ batalhão da PM é conhecido como Batalhão da Morte. Chega de esculachar a população! Chega de matarem nossos jovens". Estes fatos indicam que a morte de Marielle pode ser considerada um crime político, na medida em que a vereadora representava a voz daqueles que vivem uma forma de terrorismo de Estado no cotidiano das favelas. Para José Cláudio Alves, o assassinato de Marielle Franco assinala a 
consolidação, em um novo patamar, da estrutura do crime organizado no Rio de Janeiro e na Baixada Fluminense. De acordo com Alves, trata-se de uma

manifestação do poder de eliminação alcançado por grupos que dentro da estrutura do Estado, no caso agentes de segurança, ou articulados com estes, organizam e operam os vários negócios associados ao funcionamento de ganhos através das milícias, tráfico de drogas, execução sumária e as mais diferentes práticas de roubo. A eliminação de Marielle abre uma etapa mais profunda na intensificação, ousadia e certeza de impunidade destes grupos, revelando a fragilidade e vulnerabilidade à qual a sociedade em geral, mas principalmente os que se contrapõem aos interesses destes grupos, estão expostos. O terror e o medo são potencialidades numa nova etapa. Há uma clara mensagem a todos os que lutam pelos direitos humanos ${ }^{12}$.

Marielle sintetiza a necessária abordagem interseccional nos estudos feministas e na elaboração das políticas públicas relacionadas ao direito à vida urbana renovada. Sua existência mostra a urgência da luta pela vida de mulheres negras ${ }^{13}$. Uma luta de mulheres que pensam o direito à favela, como direito à cidade; que lutam contra o racismo em um país que entre os anos de 2002 e 2013, teve um aumento de assassinatos de mulheres negras ampliado em mais de 54\%; de mulheres que lutam contra o lesbocídio (assassinatos de lésbicas), contra a transfobia e a homofobia, contra a intolerância religiosa, contra o racismo institucionalizado em sistemas jurídicos e naturalizado no cotidiano e contra as violações sofridas pelas mães dos jovens negros assassinados ${ }^{14}$.

\footnotetext{
${ }^{12}$ FACHIN Patrícia. Marielle e os dois pilares do poder: o patriarcado e o Estado penal racista. Entrevista com José Claudio Alves. Rede Brasil Atual. 26 Mar. 2018. Disponível em: <http://www.ihu.unisinos.br/159-noticias/entrevistas/577270-a-execucao-de-marielle-e-ofortalecimento-do-crime-organizado-por-dentro-do-estado-entrevista-especial-com-jose-claudioalves-e-alana-moraes>. Acessado em: 30 Mar 2018.

${ }^{13} \mathrm{O}$ dia 14 de março foi inclú́do no calendário oficial do Estado do Rio de Janeiro como o Dia Marielle Franco - Dia de Luta contra o genocídio da Mulher Negra, por meio da Lei 8.054/18.

${ }^{14}$ Ativistas das organizações Criola e Geledés produziram um dossiê sobre a violência sofrida por mulheres negras no Brasil a partir de um relatório que foi apresentado para a Comissão Interamericana de Direitos Humanos da OEA denunciando as violações, as violências sofridas pelas mulheres negras brasileiras. Disponível em: https://racismoambiental.net.br/2016/10/02/mulheres-denunciam-a-oea-que-assassinato-contra-
} 
A violência que as mulheres sofrem no cotidiano justifica uma abordagem feminista sobre as lutas pelo direito à cidade. O machismo e o patriarcalismo interferem nas experiências de homens e mulheres no espaço e o planejamento urbano contribui para a ampliação do impacto dos papéis de gênero nos usos do território. A cidade pensada a partir dos interesses do capital não é um lugar seguro para as mulheres, que são historicamente responsabilizadas pelo cuidado (evidenciado nos atos cotidianos de levar as crianças à escola, as pessoas doentes ao atendimento médico-hospitalar, auxiliar os idosos em seu cotidiano), mas que são constantemente violentadas no caminho. As mulheres que se movem de uma zona para outra da metrópole por meio de um transporte público precário, caro e inseguro, escancaram a dissintonia entre o corpo e a materialidade urbana.

De acordo com o $11^{\circ}$ Anuário do Fórum Brasileiro de Segurança Pública (FBSP) organização não governamental (ONG) que formula análises e pesquisa as estatísticas sobre a violência no País em 2016, uma mulher foi assassinada a cada duas horas em $2016^{15}$. Tais dados apontam que a cada 11 minutos uma mulher é estuprada no Brasil. Considerando a baixa notificação, estimada em um terço dos casos, a frequência certamente é bem maior. Somente em 2014, 47,6 mil mulheres foram estupradas no país, sendo 5,7 mil casos no estado do Rio. Embora grande parte da violência contra a mulher ocorra no âmbito doméstico, sendo praticada por companheiros (namorados, maridos, ex-companheiros), a cultura machista de objetificação da mulher e a crença em um acesso irrestrito dos homens aos corpos das mulheres, somada à existência de muitos lugares e situações propícias à violência sexista (falta de iluminação pública, lotes vazios, grandes vias com pouca ou sem circulação de pedestres, longas esperas e superlotação nos transportes públicos) multiplicam os casos de abusos e assédios contra mulheres.

A violência contra lésbicas, gays, bissexuais, transexuais, travestis, transgêneros (e pessoas com identidades de gênero que subvertem $o$ binarismo e a heteronormatividade) faz uma vítima a cada 25 horas, de acordo com dados do Grupo

negras-aumentou-mais-de-50-em-10-anos Acessado em 30 de mar de 2018.

${ }^{15}$ Fórum Brasileiro de Segurança Pública. São Paulo: Fórum Brasileiro de Segurança Pública, 2017. 
Gay da Bahia ${ }^{16}$. O país que lidera o ranking mundial de assassinato da população LGBTQI+, enfrenta também a evasão escolar desta parcela da população, em especial das pessoas trans, que sofrem discriminações e estigmas no espaço escolar.

A violência é a regra da ação colonial e não a exceção. Uma proposta crítica de um feminismo decolonial da América Latina e Caribe é uma forma de destacar uma oposição ao machismo institucionalizado, mas também de questionar o feminismo ilustrado, branco, heterossexual, institucional e estatal, sendo fundamentalmente um feminismo reflexivo em que se coloca a necessidade de uma prática política aberta e pluriversa, que considere a sobreposição dos sistemas de dominação como o capitalismo, o sexismo, o racismo e a heteronormatividade.

As ações das mulheres que destacamos - no campo acadêmico e científico ou no âmbito das políticas públicas - tratam de alterações em curso não apenas na epistemologia, nas teorias e nos métodos científicos, reveladores das estruturas sociais e culturais, mas também as práticas e as ações que concretizam as transformações e conquistas feministas na vida cotidiana. Diante de tantos retrocessos, o movimento feminista revela seu papel político na luta das mulheres pelo direito à cidade e como se organizam as táticas de sobrevivência no cenário hostil que a vida social representa. Os cartazes colados nas paredes e muros da cidade pelo projeto Feminicidade alertam: "Não se faz revolução se não for feminista e aí tem que ter a nossa cor: tem que ser feminista e tem que ser negra" (Marielle Franco) ${ }^{17}$. A ação feminista revela, portanto, uma organização horizontal, solidária e espontânea, transescalar e multidirecionada como

\footnotetext{
${ }^{16}$ Dados de pesquisas realizadas pelo Grupo Gay da Bahia (GGB) mostram que no ano de 2016 foram registradas 343 mortes, entre janeiro de dezembro. Ou seja, a cada 25 horas um LGBT foi assassinado, o que faz do Brasil o campeão mundial de crimes contra as minorias sexuais. A Bahia ocupa a segunda posição entre os estados com 32 mortes, ficando atrás apenas de São Paulo (49 casos).

${ }^{17}$ Criado pelo Atados em parceria com diversos coletivos, o projeto Feminicidade mobilizou dezenas de voluntárias para ouvir histórias de mulheres pelas cidades e registrar esses depoimentos em fotografias, textos, frases e poesias, que ocupam as ruas em formas de lambes. Além das intervenções urbanas, a ação promove diálogos e debates de temas relevantes às mulheres para disseminar informações como forma de empoderamento. As frases ditas por Marielle Franco foram estampadas em cartazes (lambes) com a foto da vereadora que foram colados nas paredes e muros da cidade como forma intervenção política e cultural na cidade. Ver mais em: http://www.feminicidade.com.br.
} 
Mulheres e ação política: lutas feministas pelo direito à cidade

Anita Loureiro de Oliveira

base da luta contra o patriarcado, contra o racismo, contra o heterossexismo e contra o capitalismo. 


\section{Referências}

BERNER, Vanessa Oliveira Batista; MELINO, Heloisa. Perspectivas feministas e movimentos sociais: uma abordagem fundamental para o planejamento urbano. Revista de Direito da Cidade. v.08, n. 4, p.1868-1892, 2016.

BRASIL. Lei Maria da Penha. Lei $n^{\circ} 11.340$, de 7 de agosto de 2006. Cria mecanismos para coibir a violência doméstica e familiar contra a mulher; altera o Código de Processo Penal, o Código Penal e a Lei de Execução Penal; e dá outras providências. Disponível em: http://www.planalto.gov.br/ccivil_03/_Ato2004-2006/2006/Lei/L11340.htm Acesso em 30 de mar 2018.

BRASIL. Lei do Feminicídio. Lei n 13.104, de 9 de março de 2015. Altera o art. 121 do Decreto-Lei $n^{\circ}$ 2.848, de 7 de dezembro de 1940 - Código Penal, para prever o feminicídio como circunstância qualificadora do crime de homicídio, e o art. $1^{\circ}$ da Lei $n^{\circ} 8.072$, de 25 de julho de 1990, para incluir o feminicídio no rol dos crimes hediondos. Disponível em: http://www.planalto.gov.br/CCIVIL_03/_Ato2015-2018/2015/Lei/L13104.htm . Acesso em: 30 mar. 2018.

CASTAÑEDA Carolina. Pensamentos críticos desde e para a América Latina. In: MORAES, Alex MartinsetAl.. Pensamento descolonial e práticas acadêmicas dissidentes. Cadernos IHU, Ano 11, n.44.p. 9-15, 2013.

CARASCO, Daniela e CORTÊS, Natacha. Ser mulher no Brasil machuca: Políticas públicas deficientes e estatísticas cruéis escancaram um país omisso com a vida de suas mulheres. Publicado em 08 de março de 2018. Reportagem: Daniela Carasco e Natacha Cortêz; Edição: Vladimir Maluf; Direção de Arte: Mariana Romani; Ilustrações: Priscila Barbosa. Disponível em: https://universa.uol.com.br/especiais/ser-mulher-no-brasilmachuca/index.htm?utm_source=facebook.com\&utm_medium=social\&utm_campaign=f b-estilo\&utm_content=geral\#ser-mulher-negra-no-brasil-e-estar-a-margem-da-sociedade Acesso em: 30 mar. 2018.

CERTEAU, Michel. A escrita da história. Traduzido por Maria de Lourdes Menezes. Rio de Janeiro: Editora Forense Universitária, 1982. 315p.

CURIEL, Ochy Descolonizando el feminismo: una perspectiva desde America Latina y el Caribe. 2009. Disponível em:

<http://www.bdigital.unal.edu.co/39749/1/ochycuriel.2009.pdf.pdf>. Acesso em 20 Mar. 2018.

DAVIS, Angela. Mulheres, raça e classe. Tradução: Heci Regina Candiani. São Paulo: Boitempo, 2016.

DINIZ, Debora; MEDEIROS, Marcelo; MADEIRO, Alberto. Pesquisa Nacional de Aborto 2016. Ciênc. saúde coletiva [online]. v.22, n.2, p.653-660, 2017. Disponível em: <http://dx.doi.org/10.1590/1413-81232017222.23812016>. Acesso em: 30 mar. 2018. 
FACHIN, Patrícia. Marielle e os dois pilares do poder: o patriarcado e o Estado penal racista. Rede Brasil Atual. 26 de Março de 2018.

FEDERICI, Silvia. Calibã e a bruxa : mulheres, corpo e acumulação primitiva. Tradução: Coletivo Sycorax São Paulo : Elefante, 2017

HARAWAY, Donna. Saberes Localizados: a questão da ciência para o feminismo e o privilégio da perspectiva parcial. Cadernos Pagu. v.5, p. 07-41, 1995.

INSTITUTO BRASILEIRO DE DIREITO URBANÍSTICO (IBDU). Direito à cidade: uma visão por gênero. São Paulo: IBDU, 2017. Disponível em

<https://feminismurbana.files.wordpress.com/2017/07/direito_a_cidade_genero_ibeu1.pn g>. Acesso em: 30 mar. 2018.

INSTITUTO BRASILEIRO DE GEOGRAFIA E ESTATÍSTICA (IBGE). Pesquisa Nacional por Amostra de Domicílios: síntese de indicadores 2013. Rio de Janeiro: IBGE, Coordenação de Trabalho e Rendimento, 2014.

INSTITUTO BRASILEIRO DE GEOGRAFIA E ESTATÍ́STICA (IBGE). Pesquisa Nacional por Amostra de Domicílios: síntese de indicadores 2015. Rio de Janeiro: IBGE, Coordenação de Trabalho e Rendimento, 2016.

INSTITUTO DE PESQUISA ECONOMICA APLICADA (IPEA). Mapa da violência 2017. Rio de Janeiro: IPEA, 2017. Disponível em:

<http://www.ipea.gov.br/atlasviolencia/arquivos/downloads/8623-

170602atlasdaviolencia2017.pdf>. Acesso em: 30 mar. 2018

LEFEBVRE, Henri. O direito à cidade. São Paulo: Centauro, 2001.

LUGONES, Maria. Rumo a um feminismo descolonial. Revista Estudos Feministas.

Florianópolis, v.22, n.3, p. 935-952, set./dez., 2014.

MAPA da violência 2015: Homicídio de Mulheres no Brasil (Flacso/OPAS-OMS/ONU Mulheres/SPM), 2015.

MORAES Alex Martins et. Al. Pensamento descolonial e práticas acadêmicas dissidentes. Cadernos IHU, Ano 11. N.44, 2013. Disponível em:

<https://antropologiacritica.files.wordpress.com/2013/11/cadernos-ihu.pdf>. Acesso em: 30 mar. 2018.

OLIVEIRA, Anita Loureiro de. Por uma episteme dialógica, sensível e criativa: Uma homenagem a Ana Clara Torres Ribeiro. Revista Tamoios (UERJ/FFP), São Gonçalo (RJ), ano 08, n. 1, pags. 13-29, jan/jun. 2012 Disponível em:

<http://www.e-publicacoes.uerj.br/index.php/tamoios/article/view/3293> Acesso em: 20 jul. 2018. 
OSCAR, Raquel Cardoso. Por uma abordagem feminista dos direitos sociais, sexuais e reprodutivos. Revista Enfoques. v.15, p.74-86, dez., 2016.

PORTO-GONÇALVES, Carlos Walter. Da geografia às geo-grafias. 2001. Texto apresentado na II Conferencia Latinoamericana y Caribeña de Ciencias Sociales. Grupo de Trabajo de Economía Internacional. Universidad de Guadalajara, México. 2001.

QUIJANO, Aníbal. Colonialidade do poder, eurocentrismo e América Latina. In: LANDER, Edgardo (Org.). A colonialidade do saber: eurocentrismo e ciências sociais, Perspectivas latino-americanas. Buenos Aires, Argentina: Colección SurSur, CLACSO, 2005.

RIBEIRO, Ana Clara Torres. Sujeito corporificado e bioética: caminhos da democracia. Revista Brasileira de Educação Médica. v.24, n.1, jan./abr., 2000.

RIBEIRO, Ana Clara Torres. Sociologia do presente. Rio de Janeiro: Letra Capital, 2013.

RIBEIRO, Ana Clara Torres. Teorias da ação. Rio de Janeiro: Letra Capital, 2014.

RODRIGUES, Carla. 2017, o ano das bruxas em ação. A revolução será feminista. Le Monde Diplomatique Brasil, ano 11, n. 12b, jan., 2018.

SHIVA, Vandana. Monoculturas da mente: perspectiva da biodiversidade e da biotecnologia. Tradução Dinah de Abreu Azevedo. São Paulo: Gaia, 2003.

SHIVA, Vandana; MIES, Maria. Ecofeminismo. Tradução Fernando Antunes. Lisboa: Edições Piaget. 1997.

SILVA, Joseli Maria. Geografias subversivas: discursos sobre espaço, gênero e sexualidade. $1^{\text {a }}$ edição. Ponta Grossa, Paraná: Toda Palavra, 2009.

SILVA, Joseli Maria. Corpo, corporeidade e espaço na análise geográfica. In. HEIDRICH, Álvaro Luiz, COSTA, Benhur Pinós da, e PIRES, Cláudia Luisa Zeferino (organizadores). Maneiras de ler: geografia e cultura [recurso eletrônico] - Porto Alegre: Imprensa Livre: Compasso Lugar Cultura, 2013. Disponível em:

http://laboter.iesa.ufg.br/up/214/o/MANEIRAS_DE_LER_GEOGRAFIA_E_CULTURAL.pdf

SILVA, Joseli Maria; ORNAT, Marcio; CHIMIN JUNIOR, Alides B. Não me chame de senhora, eu sou feminista'! posicionalidade e reflexibilidade na produção geográfica de Doreen Massey. Geographia (UFF), v. 19, p. 11-20, 2017.

WALSH, Catherine. Interculturalidad, estado, sociedad: luchas (de)coloniales de nuestra época. Quito: Universidad Andina Simón Bolivar, Ediciones Abya-Yala, 2009.

WALSH, Catherine. Pedagogías decoloniales: prácticas insurgentes de resistir, (re)existir y (re)vivir. Tomo I. Quito, Ecuador: Ediciones Abya-Yala, 2013. 
